\title{
A plasmonic modulator based on metal-insulator-metal waveguide with barium titanate core
}

Babicheva, Viktoriia; Lavrinenko, Andrei

Published in:

Photonics Letters of Poland

Link to article, DOI:

10.4302/plp.2013.2.08

Publication date:

2013

Document Version

Publisher's PDF, also known as Version of record

Link back to DTU Orbit

Citation (APA):

Babicheva, V., \& Lavrinenko, A. (2013). A plasmonic modulator based on metal-insulator-metal waveguide with barium titanate core. Photonics Letters of Poland, 5(2), 57-59. https://doi.org/10.4302/plp.2013.2.08

\section{General rights}

Copyright and moral rights for the publications made accessible in the public portal are retained by the authors and/or other copyright owners and it is a condition of accessing publications that users recognise and abide by the legal requirements associated with these rights.

- Users may download and print one copy of any publication from the public portal for the purpose of private study or research.

- You may not further distribute the material or use it for any profit-making activity or commercial gain

- You may freely distribute the URL identifying the publication in the public portal 


\title{
A plasmonic modulator based on a metal-insulator-metal waveguide with a barium titanate core
}

\author{
Viktoriia E. Babicheva* and Andrei V. Lavrinenko \\ DTU Fotonik, Technical University of Denmark, Oersteds Plads 343, 2800 Kgs. Lyngby, Denmark
}

Received May 13, 2013; accepted June 28, 2013; published June 30, 2013

\begin{abstract}
We design a plasmonic modulator which can be utilized as a compact active device in photonic integrated circuits. The active material, barium titanate $\left(\mathrm{BaTiO}_{3}\right)$, is sandwiched between metal plates and changes its refractive index under applied voltage. Some degree of switching of ferroelectric domains from the in-plane to out-of-plane orientation provides the change of the refractive index, which can be exploited for effective light modulation. By numerical analysis we prove that the $\pi$ phase change can be achieved with a $12 \ldots 15 \mu \mathrm{m}$ length device having propagation losses $0.05 \ldots 0.2 \mathrm{~dB} / \mu \mathrm{m}$.
\end{abstract}

Utilizing plasmonic waves in nanostructures allows efficient manipulation of light on the subwavelength scale [1-3]. In particular, plasmonic modulators and switches are of major interest for ultra-compact photonic integrated circuits [4]. Several promising layouts have been proposed recently, which outperform conventional photonic-waveguide-based designs [5-11].

A metal-insulator-metal (MIM) waveguide provides the most compact layout [12-15]. Efficient performance is achieved because of the high field confinement between the metal layers which also serve as electrodes. For such waveguides, the mode is strongly localized within the core. Although high performance was predicted and experimentally demonstrated, a detailed characterization of the devices encounters several problems, mainly because of the small mode size and high insertion losses. Recently, it has been shown that the efficient coupling from a photonic waveguide to an MIM structure can be realized to launch the signal [16].

Different active materials have been widely studied over the last several years. Transparent conducting oxides provide a large change of refractive indexes and can be utilized for fast signal modulation [5,17-20]. However, they possess high losses, consequently the modal propagation length is fairly small $[17,19]$. Another approach is to implement gain materials and directly control the absorption coefficient [21-23]. However, such materials can increase the noise level.

Barium titanate $\left(\mathrm{BaTiO}_{3}\right)$ was shown to provide high performance for photonic thin film modulators [24-27]. Here we propose the implementation of $\mathrm{BaTiO}_{3}$ as the

\footnotetext{
*E-mail: vbab@fotonik.dtu.dk
}

active core of a MIM waveguide. Under applied voltage, some part of ferroelectric domains can be switched from the in-plane (with an ordinary refractive index $n_{\mathrm{o}}$ ) to outof-plane orientation (with extraordinary index $n_{\mathrm{e}}$ ) $[28,29]$. Thus, the refractive index for a field polarized along one axis can be changed, and control of a propagating signal is achieved. Different voltage provides a different degree of domain switching, and thus the required level of modulation can be realized. A similar option for electrooptic modulation was studied in plasmonic interferometers [30].

A schematic view of the MIM waveguide with $\mathrm{BaTiO}_{3}$ is shown in Fig. 1. We compare three metals: silver, gold, and aluminum. We are interested in modulation on the telecom wavelength only, $\lambda_{0}=1.55 \mu \mathrm{m}$, so metal parameters are fixed: $\varepsilon_{\mathrm{Ag}}=-129+3.3 \mathrm{i}$ [31], $\varepsilon_{\mathrm{Au}}=-$ $115+11.3 \mathrm{i}$ [31], and $\varepsilon_{\mathrm{Al}}=-240+49 \mathrm{i}$ [32]. Silver and gold conventionally show the best plasmonic performance. However, they are not compatible with CMOS fabrication facilities. Aluminum possesses higher losses, but it is CMOS-compatible and can be adopted in manufacturing.

$\mathrm{BaTiO}_{3}$ is highly birefringent with the refractive index difference $\Delta n=0.05$. Thus, we consider $n_{\mathrm{o}}=2.35$ and $n_{\mathrm{e}}=2.3$ [27]. We solve the dispersion equation of a threelayer structure with $\varepsilon_{\mathrm{xx}}=n_{\mathrm{o}}{ }^{2}$ and $\varepsilon_{\mathrm{zz}}=n_{\mathrm{e}}{ }^{2}$ tensor components of the permittivity of the core (see for example [33]). It corresponds to the device off-state. Under applied voltage, domains are switched and both tensor components become equal $\varepsilon_{\mathrm{xx}}=\varepsilon_{\mathrm{zz}}=n_{\mathrm{e}}{ }^{2}$.

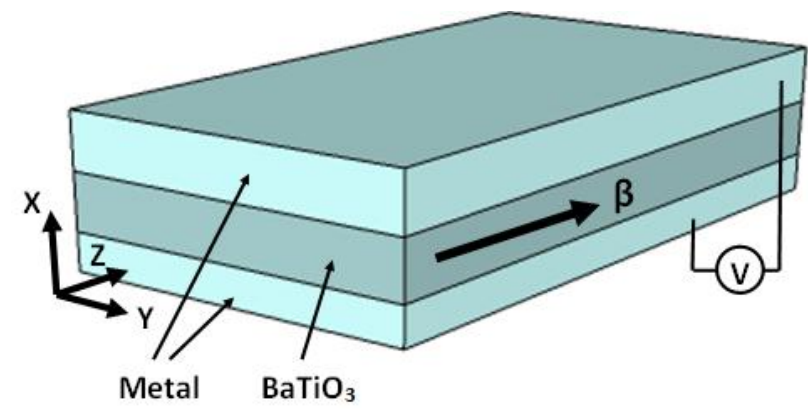

Fig. 1. Metal-insulator-metal waveguide as plasmonic modulator. 
We solved the dispersion equation for different core thicknesses $d=50 \ldots 500 \mathrm{~nm}$. Figures 2-3 show the changes of propagation constant $\beta$ and absorption coefficient $\alpha$ within the switch. The extinction coefficient of $\mathrm{BaTiO}_{3}$ is negligible, and consequently, the absorption coefficients for on- and off-states are almost the same (see Fig. 3). In contrast, the variations of $\beta$ are highly pronounced: $\beta$ varies in the range $9.5 \ldots 11.5 \mu \mathrm{m}^{-1}$ with corresponding effective index $n_{\mathrm{eff}}=2.34 \ldots 2.84$. Thus such a mode is suitable for the signal phase control.

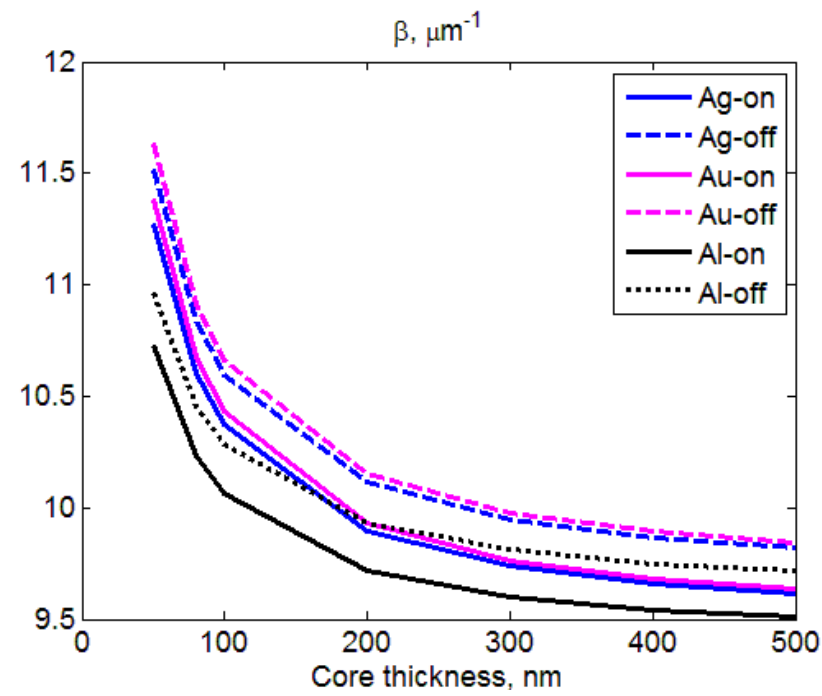

Fig. 2. Propagation constant for MIM waveguides with different metals.

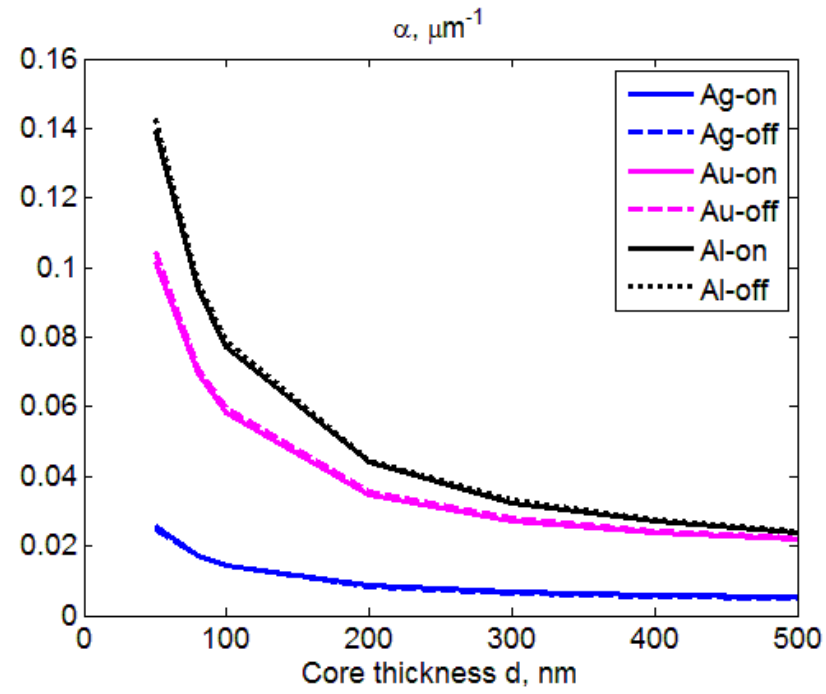

Fig. 3. Absorption coefficient for MIM waveguides with different metals.

We calculated the length of the waveguide required to achieve the $\pi$ phase change between the on- and off-states:

$$
L_{\pi}=\pi /\left(\beta_{\text {off }}-\beta_{\text {on }}\right) \text {. }
$$

It has values around $13 \ldots 15 \mu \mathrm{m}$ in the broad range of $d$ (Fig. 4). The propagation losses are $0.05 \ldots 0.2 \mathrm{~dB} / \mu \mathrm{m}$. Thus, with such a short device length $L_{\pi}$ the modulator has relatively high transmittance:

$$
T=\exp \left(-\alpha L_{\pi}\right)
$$

Aluminum has the highest absolute value of real and imaginary parts, therefore it possesses the lowest $\beta$ and highest $\alpha$ among three metals under study. Thus, the $\mathrm{Al}$ modulator has a bit higher $L_{\pi}$ and much lower transmittance.

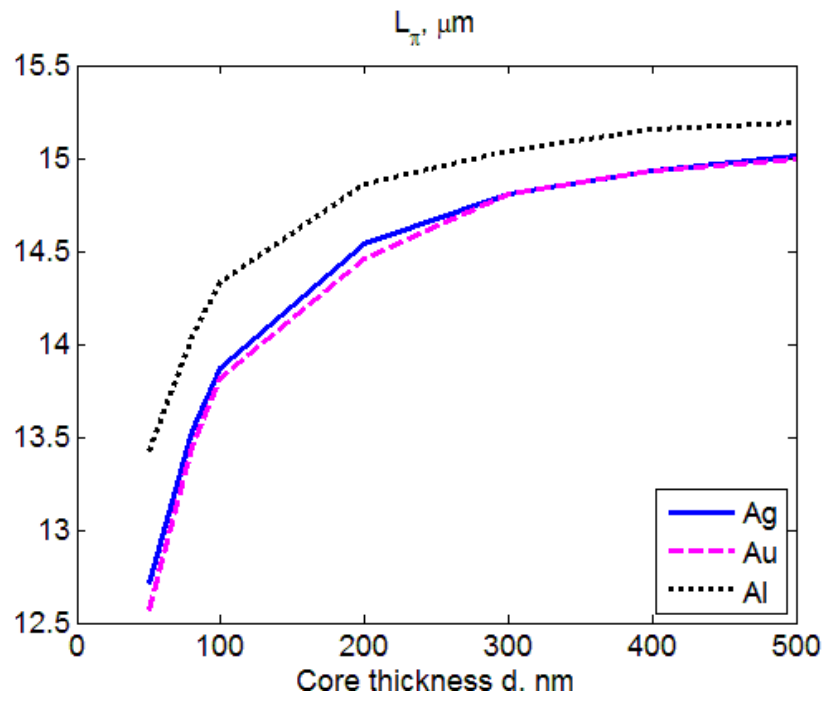

Fig. 4. Device length $L_{\pi}$ which is required to achieve $\pi$ phase difference with two states.

$L_{\pi}$ decreases with the decrease of core thickness $d$ (see Fig. 4). However, transmittance $T$ drops as well. In terms of transmittance, the modulator with silver claddings significantly outperforms others, while gold and aluminum claddings show approximately the same values for $\mathrm{d} \geq 300 \mathrm{~nm}$ (see Fig. 5).

Mach-Zehnder-interferometer-based modulators with a silicon core were theoretically studied and experimentally realized in a horizontal slot waveguide configuration [3436]. These devices demonstrate a 3-dB modulation depth having a typical length of several microns only. However, transmittance through the structures is relatively low.

Thus, adopting $\mathrm{BaTiO}_{3}$, an ultra-compact plasmonic switch can be realized. The signal phase control can be implemented via the Mach-Zehnder interferometer layout with the device length down to $12 \mu \mathrm{m}$. Mode characteristics do not have pronounced variations with different core thicknesses. The operation bandwidth is large as the $\mathrm{BaTiO}_{3}$ refractive index only slightly varies 
with the wavelength, and the effect of mode index change is essentially non-resonant.

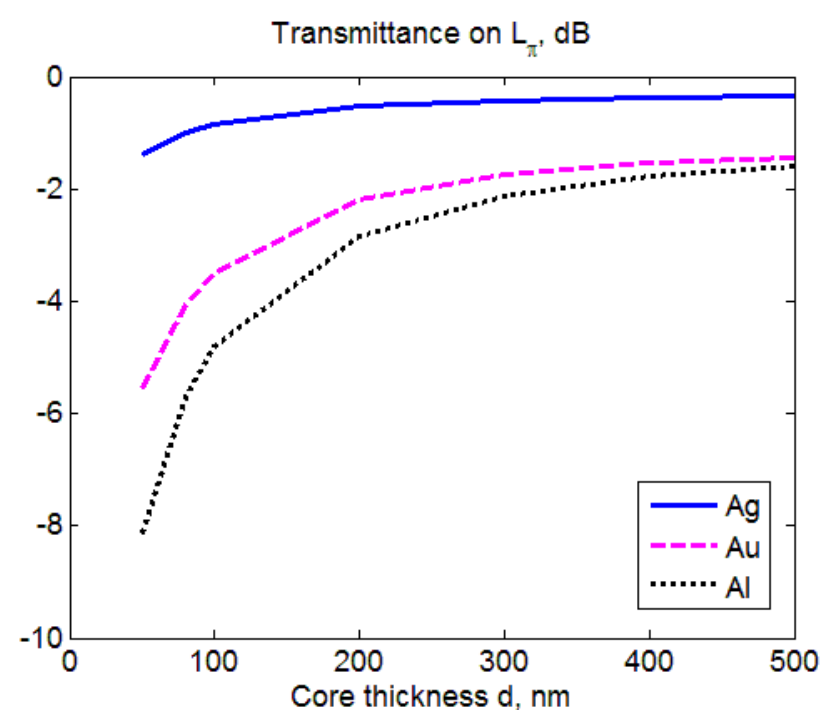

Fig. 5. Transmittance of the $L_{\pi}$-long device.

In summary, we studied the characteristics of a MIM plasmonic waveguide with a $\mathrm{BaTiO}_{3}$ core aiming to utilize it as an effective plasmonic modulator. To achieve the 3$\mathrm{dB}$ modulation depth a $12 \ldots 15-\mu \mathrm{m}$-long device is required. Such arm's length results in $-2 \ldots-4 \mathrm{~dB}$ transmittance. These parameters indicate high potential of such devices.

V.E.B. acknowledges financial support from Otto Mønsteds Fond and Thriges Fond.

\section{References}

[1] A.V. Zayats, I.I. Smolyaninov, A.A. Maradudin, Phys. Rep. 408, 131 (2005).

[2] J.A. Schuller et al., Nature Materials 9, 193 (2010).

[3] D.K. Gramotnev, S.I. Bozhevolnyi, Nat. Photon. 4, 83 (2010).

[4] K.F. MacDonald, N.I. Zheludev, Laser Photon. Rev. 4, 562 (2010).

[5] V.J. Sorger, N.D. Lanzillotti-Kimura, R.-M. Ma, X. Zhang, Nanophotonics 1, 17 (2012).

[6] H.M.G. Wassel et al., IEEE J. Emerg. Selec. Top. Circ. Syst. 2 154 (2012).

[7] W. Cai, J.S. White, M.L. Brongersma, Nano Letters 9, 4403 (2009).

[8] J.A. Dionne, K. Diest, L.A. Sweatlock, H.A. Atwater, Nano Lett. 9, 897 (2009)

[9] W. Zhao, Z. Lu, Opti. Eng. 50, 074002 (2011).

[10] B.A. Kruger et al., Opt. Expr. 20, 23598 (2012).

[11] A. Joushaghani et al., Appl. Phys. Lett. 102, 061101 (2013).

[12] J.A. Dionne, L.A. Sweatlock, H.A. Atwater, A. Polman, Phys. Rev. B 73, 035407 (2006).

[13] Y. Kurokawa, H.T. Miyazaki, Phys. Rev. B 75, 035411 (2007).

[14] B. Jaskorzynska, Y. Song, M. Qiu, Phot. Lett. Poland 1, 172 (2009).

[15] A.V. Krasavin, A.V. Zayats, Phys. Rev. Lett. 109, 053901 (2012).

[16] A. Emboras et al., Appl. Phys. Lett. 101, 251117 (2012).
[17] A. Melikyan et al., Opt. Expr. 19, 8855 (2011).

[18] V.E. Babicheva, A.V. Lavrinenko, Proc. SPIE 8424, 842413 (2012).

[19] V.E. Babicheva, A.V. Lavrinenko, Opt. Commun. 285, 5500 (2012).

[20] Zhaolin Lu, Wangshi Zhao, Kaifeng Shi, IEEE Phot. J. 4, 735 (2012).

[21] V.E. Babicheva, I.V. Kulkova, R. Malureanu, K. Yvind, A.V. Lavrinenko, Phot. Nanostr. Fundam. Applic. 10, 389 (2012).

[22] V.E. Babicheva, R. Malureanu, A.V. Lavrinenko, Proc. SPIE 8627, 86270X (2013).

[23] V.E. Babicheva, R. Malureanu, A.V. Lavrinenko, http://arxiv.org/abs/1301.5603

[24] A. Petraru, J. Schubert, M. Schmid, C. Buchal, Appl. Phys. Lett. 81, 1375 (2002).

[25] P. Tang, D.J. Towner, T. Hamano, A.L. Meier, B.W. Wessels, Opt. Expr. 12, 5962 (2004).

[26] P. Tang, D.J. Towner, A.L. Meier, B.W. Wessels, Appl. Phys. Lett. 85, 4615 (2004)

[27] P. Tang, A.L. Meier, D.J. Towner, B.W. Wessels, Opt. Lett. 30, 254 (2005).

[28] I.D. Kim, Y. Avrahami, H.L. Tuller, Y.B. Park, M.J. Dicken, H.A. Atwater, Appl. Phys. Lett. 86, 192907 (2005).

[29] M.J. Dicken, K. Diest, Y.B. Park, H.A. Atwater, J. Cryst. Growth 300, 330 (2007).

[30] M.J. Dicken et al., Nano Lett. 8, 4048 (2008).

[31] P.B. Johnson, R.W. Christy, Phys. Rev. B 6, 4370 (1972).

[32] A.D. Rakić, Appl. Opt. 34, 4755 (1995).

[33] I.D. Rukhlenko, M. Premaratne, G.P. Agrawal, Nanotechn. 23, 444006 (2012).

[34] S. Zhu, G.Q. Lo, D.L. Kwong, Opt. Expr. 18, 27802 (2010).

[35] S. Zhu, G.Q. Lo, D.L. Kwong, Appl. Phys. Lett. 99, 151114 (2011).

[36] R. Thomas, Z. Ikonic, R.W. Kelsall, Phot. Nanostr. Fundam. Applic. 10, 183 (2012). 